\title{
TOSMIC REAGENT: AN EXCELLENT PRECURSOR IN THE SYNTHESIS OF BIOLOGICALLY ACTIVE HETEROCYCLES
}

\author{
Damilola V. Aderohunmu ${ }^{1,2}$, Taiwo T. Odutola ${ }^{1}$, Olayinka O. Ajani ${ }^{1,2}$ \\ and Ezekiel F. Adebiyi ${ }^{2,3}, *$ \\ ${ }^{1}$ Department of Chemistry, CST, Covenant University, P.M.B. 1023, Ogun State, Nigeria. \\ ${ }^{2}$ Covenant University Bioinformatics Research (CUBRe), Covenant University, Km 10 Idiroko \\ Road, P.M.B. 1023 Ota, Ogun State, Nigeria \\ ${ }^{3}$ Department of Computer and Information Sciences, CST, Covenant University, P.M.B. 1023, \\ Ogun State, Nigeria \\ * E-mail: ezekiel.adebiyi@ covenantuniversity.edu.ng
}

\begin{abstract}
Heterocycles are a major material in the world today, with a wide range of applications which include pharmaceutical, cosmetics, reprography, information storage, plastics, solvents, antioxidants, corrosion inhibition among others. The $p$-toluenesulfonylmethyl isocyanide (TosMIC) is a rich-rewarding synthetic agent making it valuable template in diverse synthetic applications. Synthetic utilization of TosMIC reagent as a precursor for accessing diverse heterocyclic compounds is worthy of note in the domain of applied research. This study is, therefore, tailored at a review of the progress of the TosMIC reagent as a starting material in the synthesis of heterocycles with well-endowed pharmacological activities.

Keywords: Heterocyclic Motifs, Isocyanides, Bioactive Molecule, Cyclization, Total Synthesis.

(C) RASĀYAN. All rights reserved
\end{abstract}

\section{INTRODUCTION}

Isocyanide-initiated facile reactions are very useful in the synthesis of bioactive natural products which are a major requirement in drug development. One of such isocyanides is the TosMIC reagent which is a highly functionalized compound, containing one isocyano moiety, acidic hydrogen on the $\alpha$-carbon atom and a sulphonyl group. ${ }^{1}$ TosMIC reagent, also known as $p$-toluenesulfonyl methylisocyanide, is a crucial building block in synthetic chemistry and has been greatly engaged as an undeniable synthon for the preparation of a large array of 5-membered ring heterocycles ${ }^{2}$ and in some cases, 6-membered types. The TosMIC reagent shows four different reactivities and is suited for forming many monocyclic heterocycles and benzo-fused heterocyclic compounds including thiophene, oxazole, triazole, indoles, imidazoles, pyrroles, among other. ${ }^{3}$ In addition, it also played a salient role in the preparation of ketonic molecules through alkylation followed by hydrolysis. ${ }^{4}$

Heterocyclic chemistry has gained tremendous attention because of its unavoidable pharmacological diversity in medicinal chemistry research. ${ }^{5}$ It is to meet this large amount of needs that newer and better yielding methods of synthesizing heterocyclic compounds are continuously being sought for by organic chemists. Heterocycles are of prime importance as a sub-discipline in organic chemistry. In the world today, millions of heterocyclic compounds are known with more being synthesized on continuous bases. For instance, there is a recent synthesis of per-O-acetyl and per-O-benzoyl glycosylthiocarbamide with reported antifungal activities. ${ }^{6}$ Hence, it is worthy to note that over $80 \%$ of commercially available drugs in the current market are made up of heterocyclic compounds which is a validation of their re-occurring nature in both the chemical and biological spheres as molecules of ubiquity. Thus, it is conceivable to highlight and review the valuable role of TosMIC in the synthesis of biologically active heterocyclic compounds which are the base of drug design.

Rasayan J. Chem., 12(4), 1919-1926(2019)

http://dx.doi.org/10.31788/RJC.2019.1245315

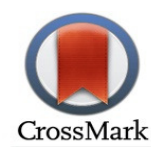




\section{Discovery of TOMIC Reagent}

The word TosMIC which is going to be used for the sake of brevity, is an acronym obtained by systematic combination of the trivial name Tosyl Methyl IsoCyanide as shown in the bracket (Tos $+\mathrm{M}+$ I + C) which has IUPAC name 1-(isocyanomethyl sulfonyl)-4-methylbenzene ${ }^{7}$ is a reagent created by Dutch chemist, Prof. Leusen. It is of great application in organic synthesis due to its versatility in producing diverse pharmacophoric frameworks. ${ }^{8}$

\section{Structure of TosMIC Reagent}

The common technique which inserts reactive methylene group of TosMIC is the popular van Leusen three-component reaction (vL-3CR) producing 1,4,5-trisubstituted imidazoles. ${ }^{9}$ Owing to the structural diversity of TosMIC, it possesses dual-functional reactivity which means it can initiate reaction through reactive methylene initiated or the isocyano moiety enhanced resulting in diverse structural scaffolds. ${ }^{10}$ The main functional group in isocyanide has structural representation. The nitrogen and not the carbon atom is the point of linkage of $\mathrm{CN}$ which is as present in isomeric nitrile; hence, the prefix iso. The carbon atom of the isocyano group in TosMIC often exhibits carbene-like reactivity that is reflected in the resonance structure 1a and its canonical hybrid $\mathbf{1 b}$ (Fig.-1). ${ }^{11}$

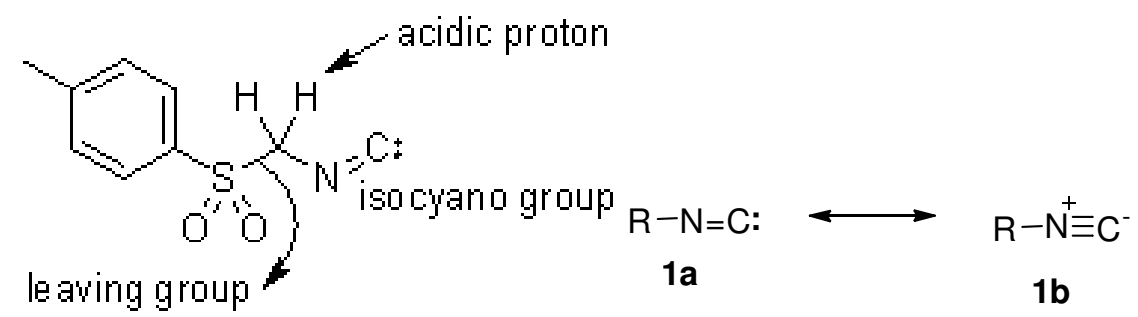

Fig.-1: Structure of TosMIC and Resonance Structures 1a and $\mathbf{1 b}$ of its Isocyanides

\section{Preparation of TosMIC Reagent}

TosMIC Reagent is prepared in a two-step reaction. The first step involved the reaction of sodium 4methylbenzenesulfinate with formamide at $90-95{ }^{\circ} \mathrm{C}$ to produce $N$-(-p-tolyl sulphonyl methyl) formamide, which consequently underwent dehydration in the presence of $\mathrm{POCl}_{3}$ to form the required TosMIC $\left(\right.$ Scheme-1). ${ }^{12}$<smiles>Cc1ccc(S(=O)(=O)[O-])cc1</smiles>

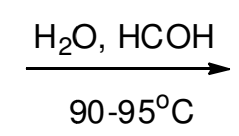<smiles>Cc1ccc(S(=O)(=O)NOC=O)cc1</smiles>

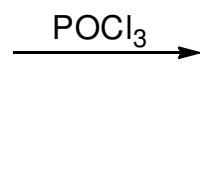

Scheme-1: Synthetic Pathway towards TosMIC Reagent<smiles>Cc1ccc(S(=O)(=O)OCC#N)cc1</smiles>

TosMIC reagent

\section{Physical Properties of TosMIC Reagents}

In terms of appearance, TosMIC reagent is a colorless, odorless solid ${ }^{8}$, which can be stored at room temperature without decomposition. TosMIC reagent is very stable, insoluble in water but relatively soluble in common organic solvents. It has a melting point of $109-113^{\circ} \mathrm{C}$ and molecular formula of $\mathrm{C}_{9} \mathrm{H}_{9} \mathrm{NO}_{2} \mathrm{~S} .{ }^{13}$ It is however, soluble in some organic solvents.

\section{Chemistry of TosMIC Reagents}

TosMIC Reagent is applicable in the synthesis of heterocycles, it serves as a cyanation reagent, connecting agent and as Umpolung reagent for the synthesis of mono or disubstituted $-\mathrm{CH}_{3}$ and $-\mathrm{CH}_{2}$ respectively, as well as in three-component Ugi reaction. ${ }^{14}$ This is due to the functional groups it contains; a sulfinyl group that functions as a labile agent and enhances the acidic potential of the $\alpha$-protons, an 
RASĀYAN J. Chem.

Vol. 12 | No. 4 |1919 - 1926| October - December | 2019

isocyanide group, whose carbon atom is the core of many reactions and an active methylene group available for secondary reactions. ${ }^{1}$ Some of the reported reaction techniques utilizing TosMIC, are Michael additions, cycloadditions and many cascade/tandem/multi- component reactions. Synthetic organic chemistry also involves selection and optimization of lead, synthesis and characterization of work for practical purposes. ${ }^{10}$

\section{General Concept for Synthesis of Heterocycles}

Heterocyclic compounds have always been a popular attraction in the field of medicinal chemistry research. ${ }^{15}$ Through the combinations of carbon, hydrogen and heteroatoms, heterocyclic compounds of diverse physical, chemical and biological properties are designed. ${ }^{16}$ The most common heterocyclic compounds are those having five- or six-membered rings and containing either, both or all of the heteroatoms - nitrogen, oxygen and sulphur. ${ }^{17}$ The general concept for the synthesis of heterocycles include the following: intramolecular substitution at saturated c-atom, intramolecular addition at carbonyl c-atom, intramolecular addition across other double bonds, cyclization at triple bonds, carbene and nitrene cyclization, electrocyclic reactions, ring closures involving ionic cyclization, important ring-closing reactions

\section{Synthesis of Heterocycles via TosMIC Reagent}

Although, various methods and techniques have been employed in the synthesis of bioactive heterocycles, the one of focus in this present work in the synthetic application of TosMIC Reagent. Despite the high versatility of TosMIC Reagent in heterocyclic synthesis, this Reagent has not been duly and resourcefully explored. Hence, it is noteworthy to expatiate on the synthesis of heterocyclic compounds by engaging TosMIC Reagent. It is also interesting to know that TosMIC has been successfully utilized in the synthesis of bioactive heterocycles such as oxazole, thiazole, pyrrole and derivatives, 1,2,4-triazole among others.

\section{Synthesis of Pyrrole Derivatives}

The Lamberth group reported that reaction of TosMIC with diethyl maleate in NaH and methyl iodide gave an intermediate dicarboxylated pyrrole which upon synthetic modification in some steps afforded the $N$-methyl-3,4-disubstituted pyrrole as shown in Scheme-2. ${ }^{18}$ It has been reported in another earlier study that sequential conjugate combination of TosMIC anion and 1-phenyl sulfonyl-1,3-butadiene was a valuable and direct route to the formation of 3,3'-bipyrrole. In a recent study, [3+2] cycloaddition with TosMICs and electron-deficient compounds provided a direct route to multi-substituted pyrrole derivatives. ${ }^{19}$

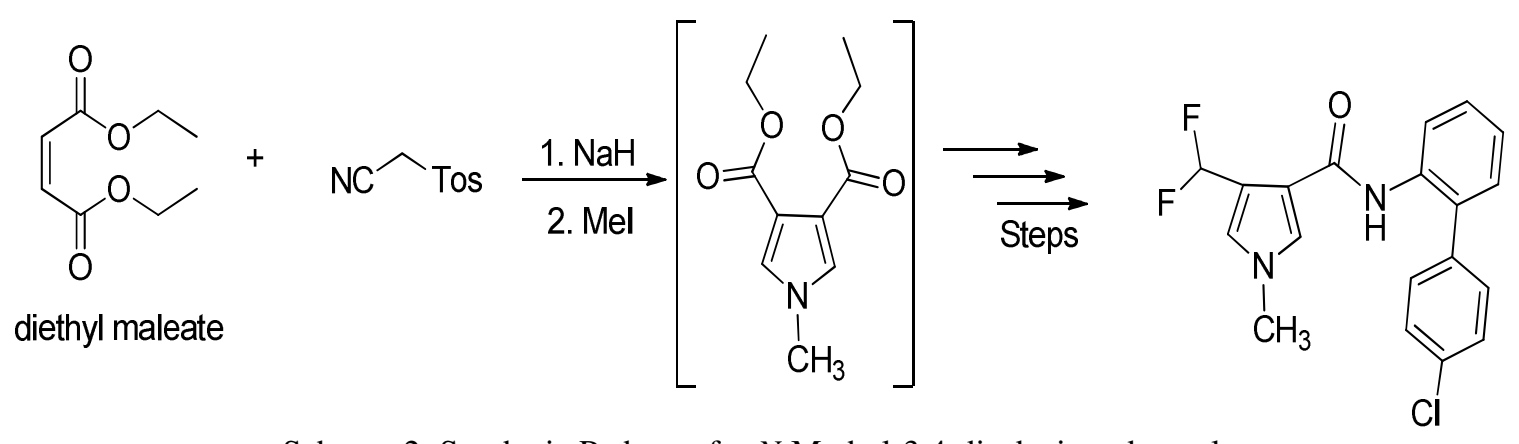

Scheme-2: Synthetic Pathway for $N$-Methyl-3,4-disubstitutedpyrrole

\section{Synthesis of Thiazole Derivatives}

One of the earliest synthetic procedures confirmed that the reaction of TosMIC with carbon disulfide will produce thiazoles. ${ }^{20}$ In Scheme-3, TosMIC conveniently reacted with carbon disulfide in the presence of chloroform, tetrabutylammonium bromide (T-BAB) and $\mathrm{NaOH}$. The intermediate thiazole product formed was successfully methylated with methyl iodide (MeI) to obtain the tosylated thiazole final product in excellent yield (90\%) after washing and recrystallization of the relevant thiazole. ${ }^{20}$ 
RASĀYAN J. Chem.

Vol. 12 | No. 4 |1919 - 1926| October - December | 2019

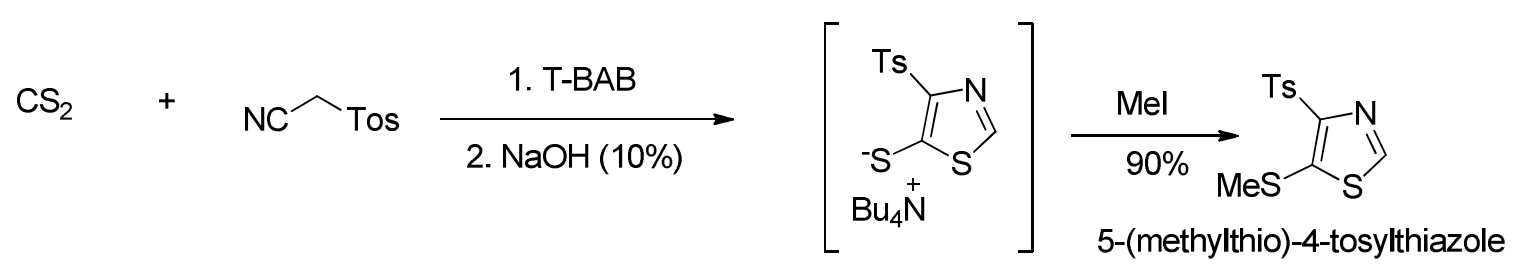

Scheme-3: Synthetic Pathway to 5-(Methylthio)-4-tosylthiazole

\section{Synthesis of Imidazole Derivatives}

Imidazole is a 5-membered heterocycle with nitrogen atoms situated in positions-1 and 3 of the ring. Earlier work of Van Leusen regarding the synthesis of 5-substituted- $N$-methylimidazole by threecomponent reaction with aldimines and TosMIC (Scheme-4) was duly captured in a recent review. ${ }^{21} \mathrm{~A}$ regioselective [3+2] annulation of $\mathrm{CH}_{2}$ of isocyanides such as TosMIC with ketenimines was achieved in the base medium using $t$-BuOK or $\mathrm{K}_{2} \mathrm{CO}_{3}$ to derived 1,4,5-trisubstituted oxadiazole. ${ }^{2}$<smiles>[R]/C=C\C</smiles>

Scheme-4: Synthetic Pathway to 5-Substituted- $N$-methylimidazole

\section{Synthesis of Oxazole Derivatives}

The treatment of cyano cyclohexane with benzoyl chloride at $60^{\circ} \mathrm{C}$ in neat condition was reported to produce an intermediate which was subsequently treated with $p$-toluenesulfonylmethyl isocyanide (TosMIC) reagent in $\mathrm{NaH}$ and tetrahydrofuran solvent at room temperature for 45 min to access biologically active 4-tosyloxazole derivatives. ${ }^{22}$ The route to the effective transformation of the intermediate through TosMIC to achieve biologically active product is as shown in Scheme-5.

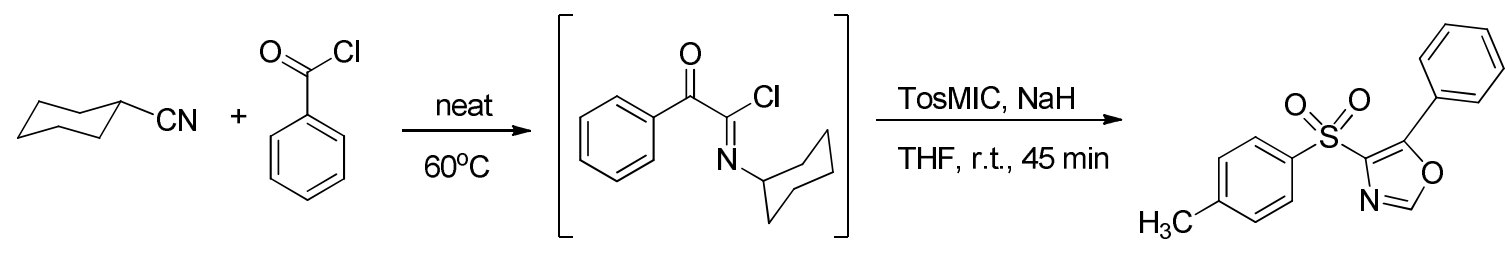

Scheme-5: Synthetic Pathway to 5-Phenyl-4-tosyloxazole

\section{Synthesis of Oxazoline Derivatives}

Facile and un-hindered access to oxazoline derivative, 4-(4-tosyl-4,5-dihydrooxazol-5-yl)phenol, have been uncovered in a recent work wherein treatment of TosMIC with aromatic aldehydes were successfully achieved in the presence of imidazole catalyst (Scheme-6). It was worthy to note that the authors of this work were able to protect the oxazoline products from oxidation by using just water as a dual-purpose agent; having utilized it has both good solvent and antioxidant. ${ }^{23}$

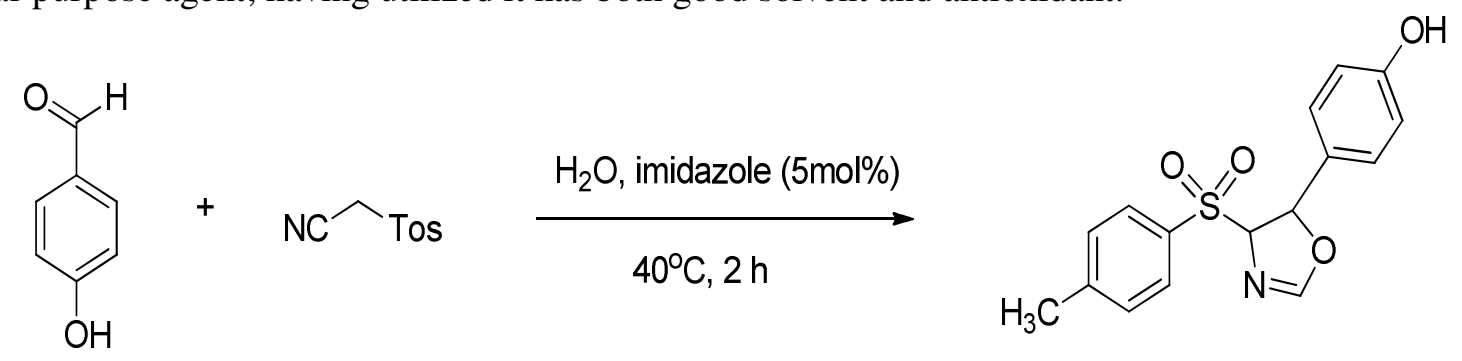

4-(4-tosyl-4,5-dihydrooxazol-5-yl)phenol

Scheme-6: Synthetic Pathway to 4-(4-Tosyl-4,5-dihydrooxazol-5-yl)phenol 


\section{RASĀYAN J. Chem.}

Vol. 12 | No. 4 |1919 - 1926| October - December | 2019

\section{Synthesis of (Z)-5-(1-Chloro-2-phenylvinyl)oxazole}

Photochemical cyclization approach for the preparation of naphtho/heterobenz[2,1-d]oxazoles was achieved through the expected 4- and 2-phenyl substituted 5-arylethenyloxazoles which were synthesized from the required $\alpha, \beta$-unsaturated aldehydes and tosylmethylisocyanide by the Van Leusen reaction as shown in Scheme-7. ${ }^{24}$

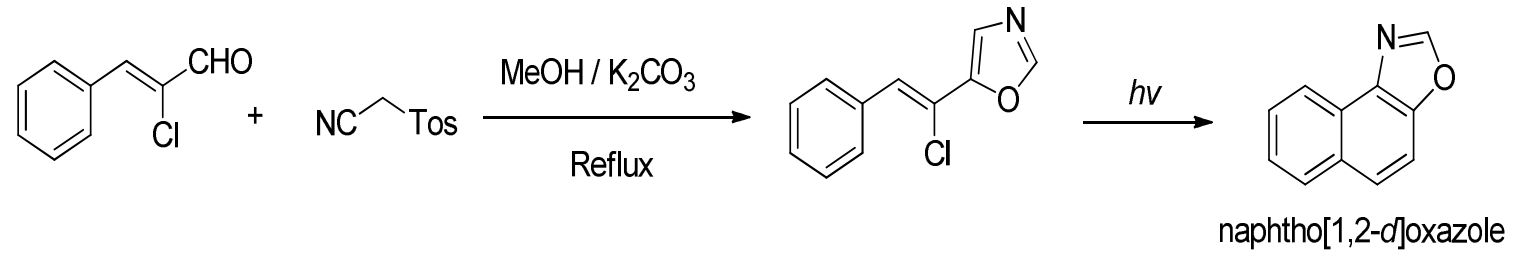

Scheme-7: Synthetic Pathway to Naphtho[1,2-d]oxazole

\section{Synthesis of Disubstituted-1,2,4-Triazoles}

TosMIC reacted with diazonium salts under controlled conditions through base-induced cycloaddition at $10^{\circ} \mathrm{C}$ using $\mathrm{K}_{2} \mathrm{CO}_{3}$ in DMSO to yield a stereoisomeric mixture of 3-tosyl-1,2,4-triazole and 5-tosyl-1,2,4triazole derivatives in $80 \%$ and $12 \%$ yields respectively. ${ }^{3}$ The reaction conditions and structural representation of the mixtures of the two products are as shown in Scheme- $8 .^{3}$

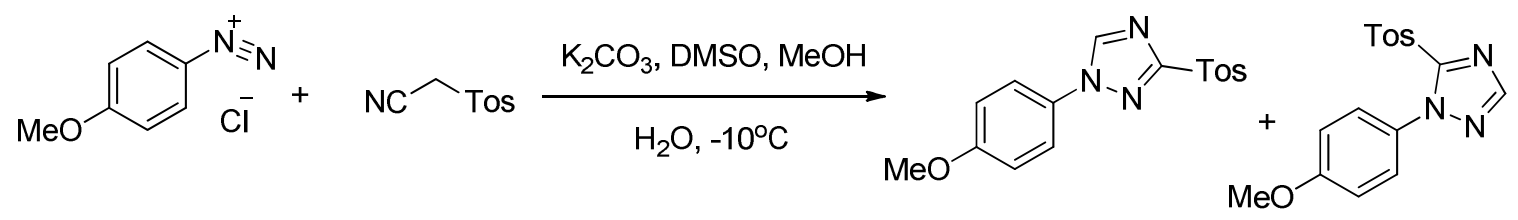

Scheme-8: Synthetic Pathway to Mixture of Tosylated-1,2,4-Triazole

\section{Synthesis of Pyrrolo[1,2-c]pyrimidines}

It is also possible to utilized TosMIC for the conversion of one small heterocycle to another bigger one. For instance, the reaction of TosMIC with pyrrole-2-carboxaldehyde in the presence of DBU base using tetrahydrofuran (THF) solvent afforded pyrrolo[1,2-c]pyrimidine. ${ }^{25}$ The reaction product was achieved in $82 \%$ through stirring of the mixture at ambient condition for $2 \mathrm{~h}$ and then neutralized with acetic acid (Scheme-9). It was recrystallized from $\mathrm{CH}_{3} \mathrm{CN}$ to give the desired product. ${ }^{25}$<smiles>[R]c1[nH]c(C=O)c([R3])c1[R2]</smiles><smiles>[R]c1c([R])c2cc([TeH])ncn2c1[R]</smiles>

Scheme-9: Synthetic Pathway to Pyrrolo[1,2-c]pyrimidines

\section{Synthesis of Indole Derivatives}

Michael acceptors and alkenyl substituted TosMIC homologs reacted to produce 2,3-dialkenyl substituted pyrroles. The trisubstituted pyrrole intermediate was made to undergo ring closure in the basified medium under UV light influence and subsequent dehydrogenation to produce tetrasubstituted indole as shown in Scheme-10. ${ }^{3}$

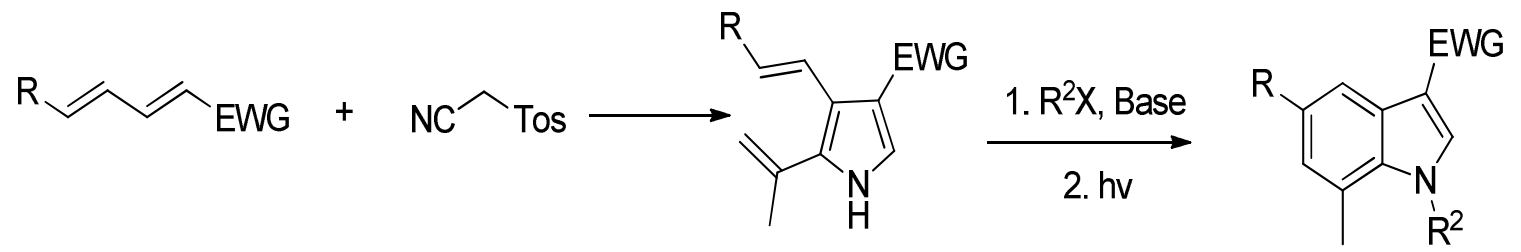




\section{RASĀYAN J. Chem.}

Vol. 12 | No. 4 |1919 - 1926| October - December | 2019

\section{Synthesis of 2-Acetylchromeno[3,4-c]pyrrol-4(2H)-one}

3-Acetylcoumain was prepared by Knoevenagel combination of ethyl acetoacetate with salicylaldehyde under the influence of piperidine catalyst as we earlier reported. ${ }^{5}$ Further treatment of 3-acetylcoumarin with TosMIC had been reported to afford 2-acetyl chromeno[3,4-c]pyrrol-4(2H)-one in the presence of triethylamine $\left(\mathrm{Et}_{3} \mathrm{~N}\right)$ and piperidine after stirring at room temperature for $8 \mathrm{~h}$ in DMF solvent (Scheme$11)^{26}$

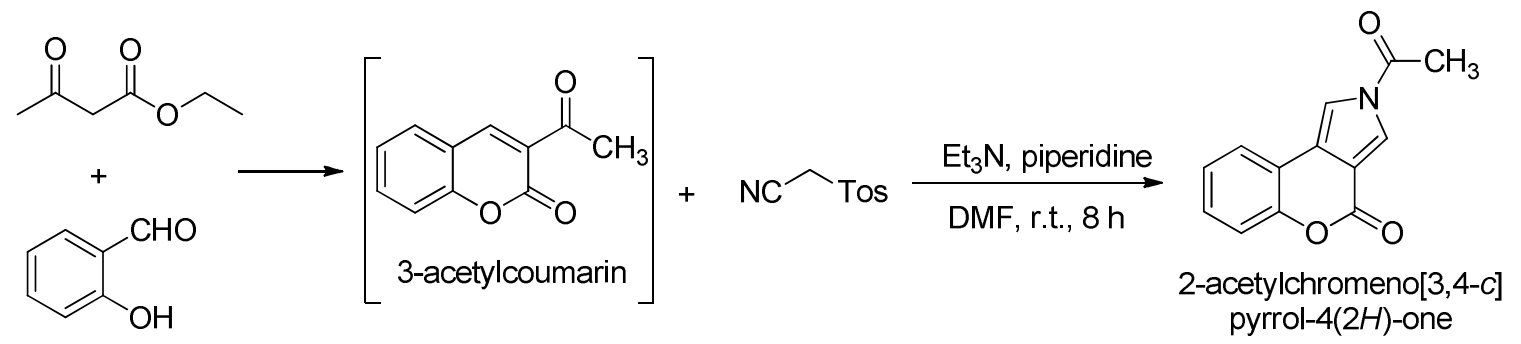

Scheme-11: Synthetic Pathway to 2-Acetylchromeno[3,4-c]pyrrol-4(2H)-one

\section{Synthesis of Isoquinoline Natural Product (Papaverine)}

TosMIC Reagent is very useful in the total synthesis of phytochemicals which are secondary metabolites such as papaverine, mansouramycin B, muscalure among others. Papaverine which is an approved drug template in the treatment of gastrointestinal tract and in muscle relaxation was synthesized by a reaction of veratraldehyde with TosMIC. The isonitrile derivative formed is reacted with veratraldehyde acetal in $\mathrm{CF}_{3} \mathrm{COOH}$, towards accessing an amide derivative which is subsequently transformed to papaverine which is an isoquinoline derivative (Scheme-12). ${ }^{27}$

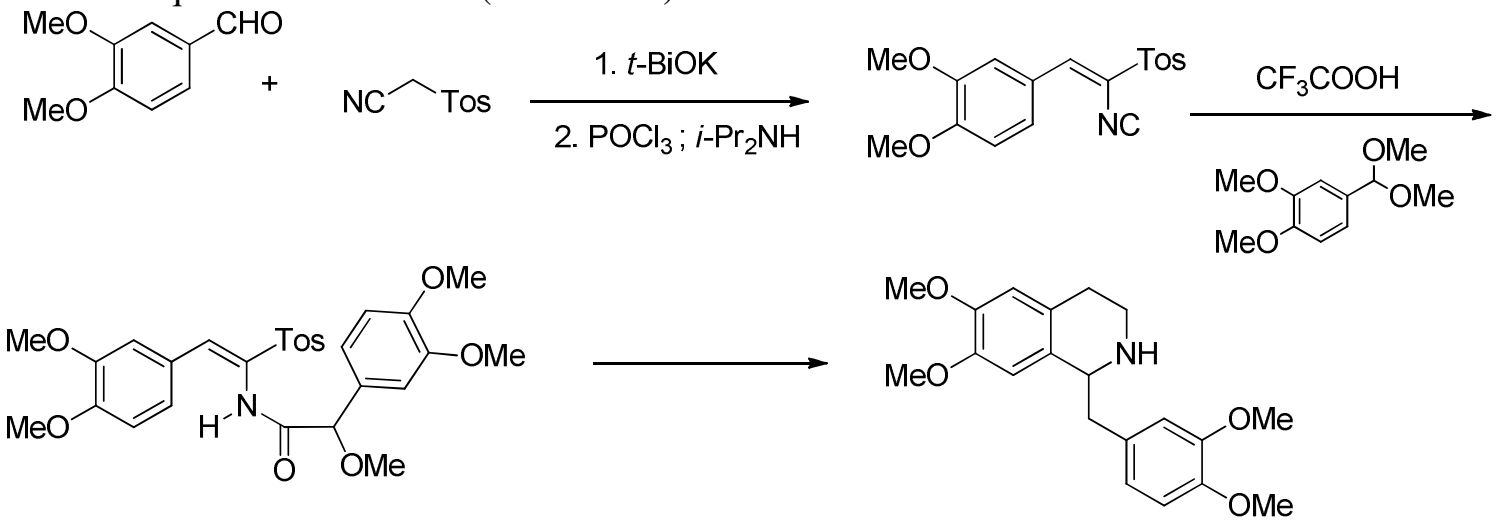

Scheme-12: Synthetic Pathway to Papaverine

\section{Selected Bioactive Heterocycles accessible via TosMIC}

Indole-3-ethanamide chromophore $\mathbf{1}$ which was accessed through the condensative reaction of Tosylmethylisocyanide with 3 -formylindole was an antifungal drug. ${ }^{28}$ TosMIC provided the essential support in the synthesis of $\mathbf{2}$ which was reported to possess antidiabetic activity by targeting the target glucose-6-phosphate translocase. ${ }^{9}$ Vertex's hepatitis C drug candidate VX-497, merimepodib 3 was prepared by the condensation of the aldehyde with TosMIC to afford the expected oxazole 3 . $^{29}$ The imidazole derivative 4 was reported to be potent anticancer agent with $\mathrm{IC}_{50}$ of $0.46 \mathrm{M}^{21}$ Total synthesis of Mansouramycin B, which was a potent antibiotic and antitumor agent, was achieved through TosMIC route. $^{30}$ In similar manner papaverine which was designed and prepared through TosMIC route is a muscle relaxant drug (Fig.-2).

\section{CONCLUSION}

TosMIC is specially, interesting because of its magical potential in the synthesis of bioactive heterocycles and other organic scaffolds used in drug design. Heterocyclic compounds are the structural framework in therapeutic medicine for drug design and development. Based on their widespread application in medicinal chemistry research, an array of literature has been accumulated. It is, therefore, very crucial to create more awareness in the potential utilization of TosMIC reagent in development of new series of 
RASĀYAN J. Chem.

Vol. 12 | No. 4 |1919 - 1926| October - December | 2019

biologically active heterocycles to help the man in his continuous combat against microbial infections and various terminal diseases.
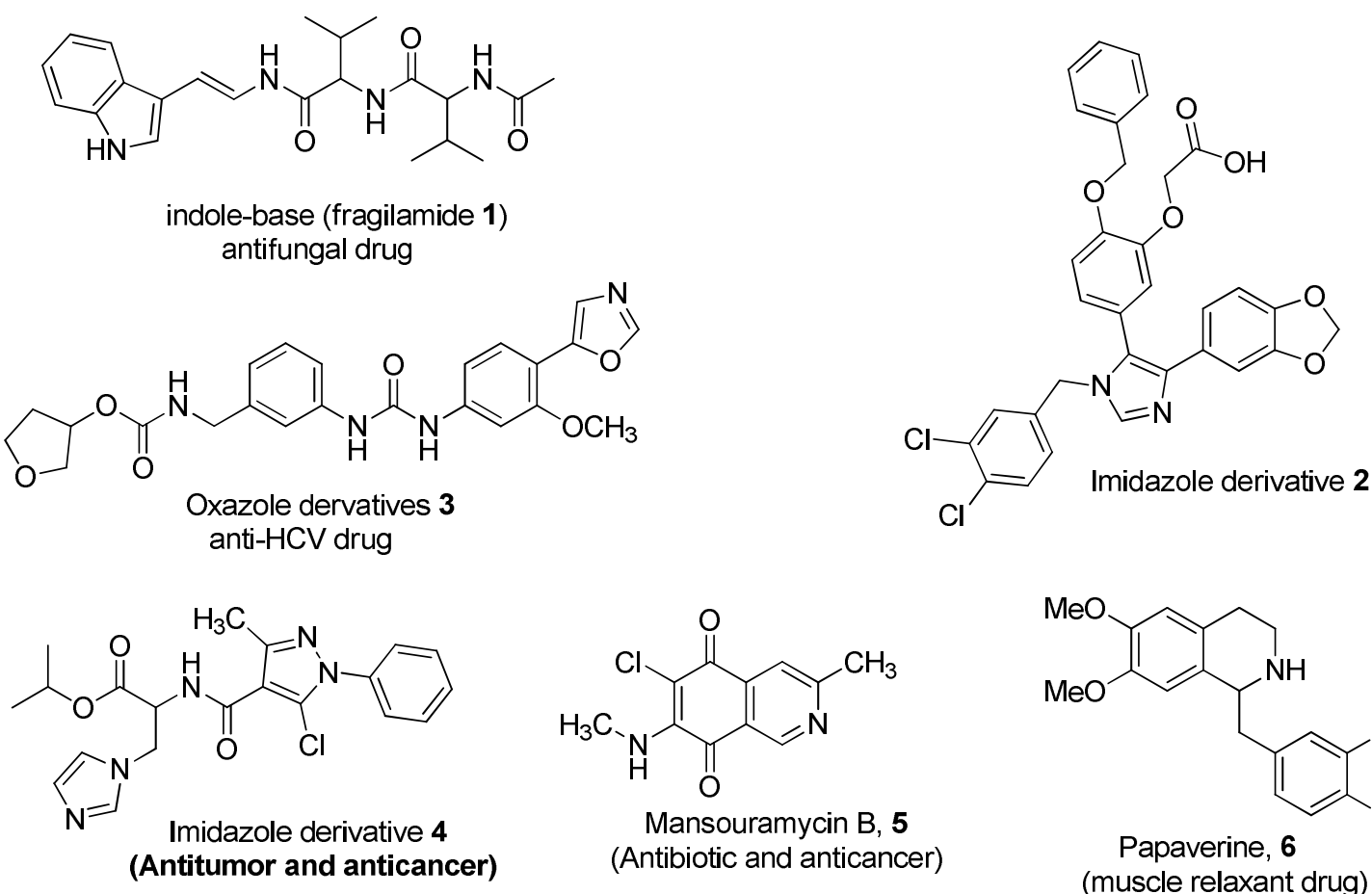<smiles>COc1ccc(CC2NCCc3cc(OC)c(OC)cc32)cc1OC</smiles>

Papaverine, 6 (muscle relaxant drug)

Fig.-2: Some Heterocyclic Compounds with Notable Biological Activities

\section{ACKNOWLEDGMENT}

This work was supported by the National Institutes of Health (Grant No: 1U2RTW010679). Covenant University is gratefully acknowledged for the support for this work.

\section{REFERENCES}

1. P. R. Krishna, E. R. Sekhar, and Y. L. Prapurna, Tetrahedron Letters, 48, 9048(2007), DOI:10.1016/j.tetlet.2007.09.164.

2. J. Cai, H. Bai, Y. Wang., X. Xu, H. Xie, and J. Liu, Chemical Communication, 55, 3821(2019), DOI:10.1039/c9cc01257e.

3. Synthatex Fine Chemicals Ltd., 2018. Tos MIC and derivatives in organic synthesis, Accessed October 12, 2018. Available online at www.synthatex.com

4. A. Dömling, Toluenesulphonylmethyl isocyanide (TOSMIC) and the Van Leusen MCR. Organic Chemistry Highlights, 2005, Available online at http://www.organicchemistry.org/Highlights/2005/05May.shtm

5. O.O. Ajani, O. Ajayi, J.A. Adekoya, T.F. Owoeye, B.M. Durodola, and O.M. Ogunleye, Journal of Applied Sciences, 16(3), 77 (2016), DOI:10.3923/jas.2016.77.87.

6. S.S. Kadu and G.V. Korpe, Rasayan Journal of Chemistry 12(3), 1058 (2019), DOI:10.31788/RJC.2019.1235128.

7. NextBio, 2018. Accessed October 16, 2018, Available online at www.nextbio.org

8. D. van Leusen, and A.M. van Leusen, Organic Reactions, 57, 419 (2001), DOI:10.1002/0471264180.or057.03.

9. S. Bräuer, M. Almstetter, W. Antuch, D. Behnke, R. Taube, P. Furer, and S. Hess, Journal of Combinatorial Chemistry, 7, 218 (2005), DOI: 10.1021/cc049867+

10. B. Geetha, G. Swarnalatha and G.V. Subba Reddy, Rasayan Journal of Chemistry, 12(3), 1063 (2019), DOI:10.31788/RJC.2019.1235165a. 


\section{RASĀYAN J. Chem.}

Vol. 12 | No. 4 |1919 - 1926| October - December | 2019

11. A. Lygin, Ph.D Thesis, Department of Chemistry, Georg-August-Universität, Göttingen,Germany (2009).

12. B. Hoogenboom, O. Oldenziel, and A.M. Leusen, Organic Syntheses Collection, 6, 987 (1988), DOI: 10.15227/orgsyn.057.0102.

13. ChemExper Chemical Directory, 2018, Accessed October 10, 2018, Available online at http://www.chemexper.com/chemicals/supplier/cas/36635-61-7.html

14. C.G. Neochoritis, D. Livadiotou, V. Tsiaras, T. Zarganes-Tzitzikas, and E.Samatidou, Tetrahedron, 72(33), 5149 (2016), DOI:10.1016/j.tet.2016.07.013.

15. O.O. Ajani, F.E. Owolabi, G.E. Jolayemi, I.O. Olanrewaju, and D.V. Aderohunmu, Rasayan J. Chem., 10(4), 1402 (2017), DOI:10.7324/RJC.2017.1041816.

16. E. Vitaku, D.T. Smith, and J.T. Njardarson, Journal of Medicinal Chemistry, 57(24), 10257 (2014), DOI:10.1021/jm501100b.

17. K. Fauché, L. Nauton, L. Jouffret, F. Cisnetti, and A. Gautier, Chemical Communications 53, 2402(2017), DOI:10.1039/c6cc09160a.

18. H. Walter, C. Lamberth, and C. Corsi, Monatshefte Chemie, 149(4), 791 (2018), DOI: 10.1007/s00706-017-2101-y.

19. Z. Ma, Z. Ma, and D. Zhang, Molecules, 23(10), 2666 (2018), DOI:10.3390/molecules23102666.

20. A. Leusen, J. Wilderman, and H. Oldenzeil, Journal of Organic Chemistry, 42(7), 1153(1977), DOI: $10.1021 /$ jo00427a012.

21. I. Ali, M.N. Lone, and H.Y. Aboul-Enein, Medicinal Chemistry Communications, 8(9), 1742 (2017), DOI:10.1039/c7md00067g.

22. M. Talebizadeh, A. Darehkordi, and M. Anary-Abbasinejad, Arkivoc, v, 194 (2018), DOI: 10.24820/ark.5550190.p010.556.

23. R. Abraham, P. Prakash, K. Mahendran, and M. Ramanathan, Arabian Journal of Chemistry, (2018), DOI:10.1016/j.arabjc.2018.03.022

24. I. Šagud, M. Šindler-Kulyk, I. Škorić, V. Kelava, and Ž. Marinić, European Journal of Organic Chemistry, 3326 (2018), DOI:10.1002/ejoc.201800737.

25. J.M. Minguez, J.J. Vaquero, J.L. Garcia-Navio, and J. Alvarez-Builla, Tetrahedron Letters, 37(24),4263 (1996), DOI:10.1016/0040-4039(96)00812-x.

26. A. Shaabani, H. Sepahvand, A. Bazgir, and H.R. Khavasi, Tetrahedron 74, 7058 (2018), DOI:10.1016/j.tet.2018.10.039.

27. C.D. Gilmore, K.M. Allan, and B.M. Stoltz, Journal of the American Chemical Society, 130, 1558 (2008), DOI: $10.1021 / \mathrm{ja} 0780582$.

28. B. Beck, S. Hess, and A. Dömling, Bioorganic and Medicinal Chemistry Letters, 10(15), 1701 (2000), DOI:10.1016/s0960-894x(00)00305-x

29. R.J. Herr, D.J. Fairfax, H. Meckler, and J.D. Wilson, Organic Process Research and Development, 6(5), 677 (2002), DOI:10.1021/op025546f.

30. A. Coppola, D. Sucunza, C. Burgos, and J.J. Vaquero, Organic Letters, 17(1), 78 (2015) DOI:10.1021/ol5032624.

[RJC-5315/2019] 